\title{
Psychological Distress Among College Youth as a Function of Family SES: The Mediating Effect of Sense of Poverty and the Mitigating Role of Family Resources
}

\author{
Melissa Lopez Reyes and Isabelle C. Yujuico \\ De La Salle University, Manila, Philippines
}

\begin{abstract}
A Ithough college provides an opportunity for socioeconomic advancement, poor college youth confront material scarcity and financial problems and are at risk for psychological distress. Yet, distress is a product not only of poverty per se but of a sense of poverty, or a subjective evaluation of one's socioeconomic conditions vis-à-vis life circumstances. Both sense of poverty and psychological distress, however, can be mitigated by collective problem-solving in the family and by the family's social resources. Analysis of data from Filipino college youth $(n=831)$ shows that the family's inability to meet financial obligations is not directly associated with distress, but indirectly through sense of poverty. Lack of family assets is not a predictor of psychological distress, given that the positive indirect effect through sense of poverty is counteracted by a negative direct effect. Results also show that family problem-solving lessens psychological distress and that adequate access to social resources lessens the negative effect of sense of poverty on distress.
\end{abstract}

Keywords: college youth, family SES, psychological distress, sense of poverty, social resources

The almost universal regard for college education as an investment with guaranteed financial returns has gained empirical support in multi-country studies (Blöndal, Field, \& Girouard, 2002; Psacharopoulos, 1994). The private returns of college education, however, are low in countries with low per capita income (Psacharopoulos, 1994) and socioeconomically disadvantaged college students face even less promising financial prospects given their relatively low graduation rates (McDonnough, 1997).

Even as severe material poverty threatens the wellbeing of a disproportionately large number of the world's youth (Moore, 2005), material scarcity among the better off college students remains an important research and policy issue in life course poverty. It is also a mental health issue, given evidence that the stress associated with being poor is, in itself, a critical mental health risk (American Psychological Association [APA] Task Force for Socioeconomic Status, 2007). That psychological distress is experienced by poor college youth is suggested by the evidence that adolescents with low socioeconomic status (SES) have low levels of self-esteem and self-worth and high levels of depression and anxiety (McLeod \& Owens, 2004).

The difficult circumstances that low-SES college youth face contribute to their psychological distress. Those who work have less time left for studies and extracurricular activities (Walpole, 2003, 2008), and those enrolled in elite colleges feel a low sense of belongingness and academic fit (Johnson, Richeson, \& Finkel, 2011). Completing one's college education also becomes daunting in the face of fewer educational resources, lack of parental help in college-related goal setting, and the need to stop schooling to provide for the family (Blustein et al., 2002).

\section{Sense of Poverty Mediates the Influence of Family SES on Psychological Distress}

Apart from these difficult circumstances, it is the internalisation of these circumstances and of one's belonging to a lower social class that brings about psychological distress (APA Task Force on Socioeconomic Status, 2007; Russell, 
1996). Blaming oneself for being poor, for example, has been shown to lead to lower levels of psychological wellbeing (Shek, 2004).

Thus, despite the multidimensional array of SES indicators, researchers still see the importance of a subjective evaluation of SES (de Vos \& Garner, 1991), such as asking respondents whether they consider themselves 'poor', 'borderline', or 'not poor' (Mangahas, 1999), or having respondents locate themselves in a 10-rung SES ladder (Singh-Manoux, Marmot, \& Adler, 2005). Compared to objective SES indicators, subjective evaluations of SES are more highly correlated with a variety of outcomes (Adler, Epel, Castellazo, \& Ickovics, 2000; Ostrove \& Long, 2007; Singh-Manoux et al., 2005), in particular, with one's sense of self and worldview (Diemer \& Ali, 2009). More than does reporting objective SES indicators (e.g., income, properties), subjectively evaluating one's SES entails reflecting on one's socioeconomic circumstances (Singh-Manoux et al., 2005), determining one's socioeconomic expectations vis-à-vis other people's lifestyles (The World Bank, 2001a), and identifying oneself with a particular social class (Diemer \& Ali, 2009; Ostrove \& Long, 2007).

Could poor college youth's psychological distress be rooted not only in poverty per se, but also in a keen sense of poverty? Aside from experiencing the problems of the poor in general, poor college youth have problems unique to their situation, such as a sense of isolation in college where others are more materially endowed, and disidentification with their less privileged social class as they become acculturated in a more educated class (Nelson, Englar-Carlson, Tierney, \& Hau, 2006). Thus, it is possible that poverty-related stress mediates the effect of SES on wellbeing (Diemer, Mistry, Wadsworth, Lopez, \& Reimers, 2013).

\section{The Mitigating Role of Family Problem-Solving and Social Resources}

While college affords poor youth the opportunity for socioeconomic advancement (Nelson et al., 2006), this does not always materialise, perhaps because material scarcity becomes insurmountable, or perhaps because a keen sense of poverty constrains one's capacities. Yet, there are social resources that could mitigate the effects of poverty, and of a sense of poverty, on youth's wellbeing.

These resources may come in the form of social services provided by government and institutions. With access to social services, quality of life and wellbeing are directly enhanced (Hudson, 2006). Education and health services increase the poor's labour returns in the market (The World Bank, 2001b) and subjective poverty is lessened (Jansen, Moses, Mujuta, \& Yu, 2013).

Social resources also come in the form of social networks (Kanazawa \& Savage, 2009; Valencia-Garcia, Simoni, Alegria, \& Takeuchi, 2012). Social connections serve as a means for obtaining material resources, such as jobs and loans (Harper, Marcus, \& Moore, 2003), especially during financially difficult times (Hill, Jobling, Pollet, \& Nettle, 2014). They also help prevent poverty's untoward psychological effects (Harper et al., 2003).

The collective capabilities of a social group are also social resources (Oakes \& Rossi, 2003) and these may well reside in the families themselves. Included in Walsh's (2003) family resilience-enabling skills is family problem-solving, which involves collective decision-making, goal-setting, and conflict management. Through family problemsolving, family members adapt more easily to stressors and challenges (Walsh, 2003).

Thus, college youth are not without familial and social resources for navigating their way out of poverty-related problems. These resources may result in an actual decrease in youth's sense of poverty and psychological distress, or at least lessen the effect of family SES on sense of poverty, and the effect of sense of poverty on psychological distress.

\section{Objectives of the Current Research}

The Philippines is an apt context for studying the experience of poverty. Classified by the World Bank (2014) as a developing lower-middle income country, the Philippines had a poverty incidence rate of $25 \%$ in 2012 and an average self-rated poverty rate of $41 \%$ in 2013 (Romulo, 2014). A measure of a country's income inequality, the Gini ratio of the Philippines, is currently .44; this has been rising during the past three decades (Sicat, 2014) and is among the highest in Southeast Asia (National Statistical Coordination Board, 2014).

The lack of basic services hinders Filipinos from rising out of poverty (Tuason, 2002) and poor Filipinos have expressed disillusionment with the country's political, economic, and social conditions (Guerrero, 1973). Instead of relying on government, the poor depend on their families and personal contacts for financial assistance (Tuason, 2002, 2008). Thus, in explaining their poverty, or their way out of poverty, Filipinos would refer to personal, familial factors more than to social, cultural factors (Tuason, 2008).

In a country with high poverty incidence, it would be of interest to examine college youth, as they form a sector that has good chances of advancing through the SES ladder. The current research examines whether family SES indirectly predicts youth's psychological distress through the youth's sense of poverty. It also examines whether family problem-solving skills and access to social resources lessen the effect of SES on sense of poverty and the effect of sense of poverty on distress.

\section{Method}

The data analysed in this article came from the 2012 data set of the Youth Development Research Project of the De La Salle University Department of Psychology (DLSUPSYCH, 2012). 


\section{Participants}

Participants were obtained through nonrandomised sampling in diverse locations. In all, valid data were obtained from 831 participants; $14 \%$ of the submitted surveys were discarded because of a significant number of missing information.

Participants were studying in Manila (58\% of the participants) or in Bacolod (42\%). Participants from Metro Manila were students of Adamson University, La Salle College Antipolo, De La Salle-Araneta University, De La Salle University-Manila, Far Eastern University, and Pamantasan ng Lungsod ng Muntinlupa. Participants from Metro Bacolod were from the University of St. La Salle.

About an equal number of participants were sampled across the year levels. Sixty-eight per cent of the participants were female; ages ranged from 15 through $22(M=$ $18.63, S D=1.45)$. Participants are younger than are reported in studies from other countries, because there were then only 10 years of Philippine basic education (The Republic of the Philippines Official Gazette, 2012).

Sixty-one per cent of Manila participants had families residing in Manila; $64 \%$ of Bacolod participants had families residing in Bacolod. Fifty-one per cent of the participants' fathers and $58 \%$ of the mothers had at least a college diploma; $35 \%$ of the fathers and $29 \%$ of the mothers were engaged in high-prestige occupations (occupational prestige as described below).

\section{Materials}

All the measures used in this study were from the Multicontext Assessment Battery of Youth Development, which was constructed for the Youth Development Research Project of DLSU-PSYCH and has been pretested with college samples (Reyes, Garo-Santiago, Sta. Maria, \& DLSUPSYCH, 2011).

Items were written in both English and Filipino. The equivalence was reviewed by two researchers who use both languages in their work. In cases of lack of congruence, they aligned the poorer version with the version that conveys the intended meaning.

Family SES. Two dimensions of Family SES were measured: family financial assets and family financial difficulties. Family financial assets were measured using possessions/conveniences and parental occupation and prestige. Ten items measured possessions/conveniences (e.g., own house, number of airconditioners). A yes-no, or a 1 through ' 5 or more', response format was used as is appropriate to the item. Six of these items have been used in the Annual Poverty Indicators Survey (National Statistics Office [NSO], 2010) and the Family Income and Expenditure Survey (NSO, 2012). The inter-item correlations were adequate with the average Gamma statistic $G$ among pairs of items equal to .33 .

Parental occupation and prestige were determined by whether the father/mother was earning regularly and, if yes, the kind of occupation performed, and whether the job was permanent. Classified as low occupational prestige were manual jobs, security services, and sales or clerical work. Classified as high occupational prestige were professional work that requires at least a college degree, organisational or corporate higher level positions, and managing proprietorship. The lowest ranked score of 1 was given if the parent was dead or was not earning regularly; higher ranked scores were given depending on the combinations of prestige, regularity, and permanency. The father's and mother's ranked scores were then summed.

Participants also indicated the highest educational attainment of each living parent. The options were elementary school diploma or lower (coded 1), high school diploma (2), vocational/technical/2-year degree/diploma (3), college diploma (4), and master's/doctoral/law/medicine (5). Parental educational attainment was the average of the parents' ranks, or the rank of the living parent.

Family financial difficulties. Family financial dificulties were measured in terms of lack of money to spend on needs, and circumstances resulting in financial difficulties. Participants indicated how often they thought their family had experienced lack of money for basic or important expenses in the past month ( 10 items; response format was 1: never to 5: very often; Cronbach $\alpha=.95)$. Participants also indicated whether or not their family had experienced, in the past 12 months, circumstances leading to financial difficulties (five items).

Sense of poverty. Participants responded yes or no to whether they considered their family poor, whether they were experiencing deplorable family conditions, and whether their basic needs were not being met. The interitem correlations were adequate with the average Gamma statistic $G$ among pairs of items equal to .56 .

Psychological distress. Participants responded yes or no to whether they were experiencing: difficulties in studying, family problems, and uncertainties about the future. They indicated the extent to which they had been experiencing, as a result of their current problems: lack of confidence in oneself and feeling downhearted (1: very weak to 5: very strong). The inter-item correlations were adequate with the average Gamma statistic $G$ among pairs of items equal to .37 .

Family problem-solving. Participants indicated extent of agreement (1: strongly disagree to 5: strongly agree) to four items describing how well family members solve problems together, support each other in their problems, and believe in their capacities to solve problems (Cronbach $\alpha=.89$; exploratory factor analysis suggests a one-factor solution with $75 \%$ of the variance in the factor explained).

Family access to social resources. Participants indicated whether or not their family has contacts to approach when looking for a job; can ask help from the barangay (a community-based political unit); can ask help from neighbours in time of need; has contacts with institutions who 
Table 1

Sets of Indicators for Which a Composite Measure was Obtained Through Nonlinear Principal Component Analysis (One-Dimensional Solution)

\begin{tabular}{|c|c|c|c|c|}
\hline Set of indicators & Scale & $\begin{array}{l}\text { Average } \\
\text { component } \\
\text { loading }^{a}\end{array}$ & Eigenvalue $^{a}$ & $\begin{array}{l}\text { Reciprocal of } \\
\text { the number of } \\
\text { indicators }\end{array}$ \\
\hline \multicolumn{5}{|c|}{ Family financial assets } \\
\hline Family possessions/conveniences & $\begin{array}{l}\text { 1: no 2: yes or } \\
\text { no. of assets (' } 5 \text { or more' is the highest response) }\end{array}$ & .61 & .40 & .10 \\
\hline $\begin{array}{l}\text { Parental occupational prestige/security and } \\
\text { educational attainment }\end{array}$ & Ranks & .85 & .72 & .50 \\
\hline \multicolumn{5}{|c|}{ Family financial difficulties } \\
\hline Difficulties in meeting family needs & 1: never to 5: very often & .82 & .69 & .10 \\
\hline $\begin{array}{l}\text { Family circumstances resulting in financial } \\
\text { difficulties }\end{array}$ & 1: did not happen 2: happened & .62 & .41 & .20 \\
\hline \multicolumn{5}{|c|}{ Other variables } \\
\hline Youth's sense of poverty & 1: no 2: yes & .72 & .53 & .33 \\
\hline Youth's psychological distress & $\begin{array}{l}\text { 1: did not happen 2: happened or } \\
\text { 1: very weak to } 5: \text { very strong }\end{array}$ & .62 & .40 & .20 \\
\hline Family problem-solving & $\begin{array}{l}\text { 1: strongly disagree to } \\
\text { 5: strongly agree }\end{array}$ & .87 & .75 & .25 \\
\hline Family access to resources & 0: no 1: yes & \multicolumn{3}{|c|}{$\begin{array}{l}\text { NPCA was not done. Composite score equals the } \\
\text { number of services that the family has access to. }\end{array}$} \\
\hline
\end{tabular}

can give them a loan; and, have access to and availment of the following services: education, scholarship, health and medical services, legal or lawyering services, social protection, and livelihood training. The measure of family access to social resources equals the total number of services checked by the respondent.

Computations of composite scores. The variables used in this study have ordinal-level indicators with different maximum scores, except the number of assets that are discretenumeric. Thus, it was not advisable to obtain composite measures through averaging. The indicators of each variable were subjected to nonlinear principal component analysis (NPCA), resulting in factor/object scores, which are the quantification of the factor underlying the indicators (de Leeuw, 2005). The factor/object score served as the composite measure for the set of indicators subjected to NPCA. Table 1 lists these sets of indicators. In all the NPCAs conducted, the one-dimensional solution resulted in adequate fit as indicated by eigenvalues greater than the reciprocal of the number of indicators (shown in Table 1).

\section{Procedure}

Permission to administer the scales was obtained from university administrators or from faculty members from whose classes the participants were recruited. The survey was paper based and self-administered. Both English and Filipino versions of the items were presented,with the Filipino version italicised and shown right below the English version. Participants answered the scales on campus and in groups after the purpose of the study was explained to them.

\section{Results}

\section{Preliminary Analyses}

Across variables, there were no significant differences between the Manila and Bacolod samples, except that the Bacolod sample reported having fewer possessions/conveniences, a keener sense of being poor, and having greater access to social resources. These observed differences between the Manila and Bacolod samples were consistent with the difference between these two cities' average annual family income: 379,000 pesos (approximately USD 8,975) for Metro Manila, and 202,000 pesos (approximately USD 4,783) for Western Visayas, where Metro Bacolod is located (NSO, 2012). The test for the equality of correlation matrices from different populations, however, did not show differences between the Bacolod and Manila samples, $\chi^{2}(15)=23.61, p=.07$. In the path analysis done, locale was included as predictor.

Confirmatory factor analysis was conducted on possessions/conveniences, parental occupation/education, difficulties in meeting needs, and circumstances likely to result in financial difficulties. A correlated two-factor model with the factor 'assets' (possessions/conveniences and occupation/education) and the factor 'difficulties' (difficulties, circumstances) had adequate fit, $\mathrm{CFI}=.99, \mathrm{SRMR}=.01$, RMSEA $=.07$ with $90 \%$ CI of $[.02, .13], \chi^{2}(1)=4.96$. This fit was better than that for a one-factor model, CFI $=.96, \mathrm{SRMR}=.03, \mathrm{RMSEA}=.12$ with $90 \% \mathrm{CI}$ of $[.08$, $.16], \chi^{2}(2)=25.53$.

Thus, two separate indicators of family SES were used in the analyses: assets, which was the average of the possessions/conveniences and occupation/education scores; and difficulties, which was the average of the scores for difficulties in meeting needs and family circumstances resulting in financial difficulties. 
Table 2

Intercorrelations Among the Variables in the Study

\begin{tabular}{|c|c|c|c|c|c|c|c|c|}
\hline & Variable & 1 & 2 & 3 & 4 & 5 & 6 & 7 \\
\hline 1. & Locale $^{a}$ & - & & & & & & \\
\hline 2. & Family financial assets & .06 & - & & & & & \\
\hline 3. & Family financial difficulties & $-.07^{*}$ & $-.47^{*}$ & $\underline{-}$ & & & & \\
\hline 4. & Youth's sense of poverty & $-.11^{*}$ & $-.31^{*}$ & $.43^{*}$ & - & & & \\
\hline 5. & Youth's psychological distress & -.02 & -.03 & $.11^{*}$ & $.34^{*}$ & - & & \\
\hline 6. & Family problem-solving & -.03 & .06 & -.06 & $-.12^{*}$ & $-.20 *$ & - & \\
\hline 7. & Family access to resources & $-.09 *$ & $.11^{*}$ & $-.08 *$ & $-.07^{*}$ & -.04 & $\overline{.11} *$ & 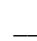 \\
\hline
\end{tabular}

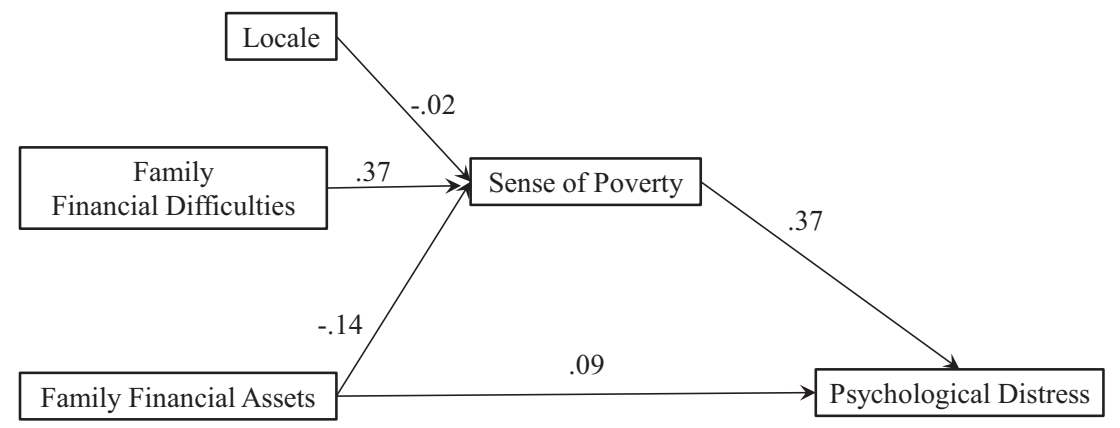

Figure 1

Reduced path-analytic model with sense of poverty mediating the relationships between family SES and psychological distress.

Shown in Table 2 are the pairwise correlation coefficients among the variables analysed.

\section{Sense of Poverty as a Mediator Between Family SES and Psychological Distress}

A path-analytic model was run to determine whether sense of poverty mediated the relationship between SES and distress. In this model, the dependent variable was distress and the exogenous variables were locale, financial assets, financial difficulties, and sense of poverty. The direct paths to sense of poverty were from locale, assets, and financial difficulties; the direct paths to distress were from sense of poverty, locale, assets, and financial difficulties.

A reduced model was obtained by removing paths that were not significantly different from zero (see Figure 1). The reduced model had adequate fit, $\mathrm{CFI}=1.00, \mathrm{SRMR}$ $=.003$, RMSEA $=.00$ with a $90 \%$ confidence interval of $[.00, .03], \chi^{2}(2)=0.17$.

Financial difficulties directly, positively predicted sense of poverty that, in turn, directly, positively predicted distress. The indirect effect (.14) of financial difficulties on distress through sense of poverty was significant $(p=.00)$. Financial difficulties did not directly predict distress.

The direct effect of assets on distress was significant and positive with greater financial assets associated with greater psychological distress. On the other hand, the indirect effect of assets on distress through sense of poverty was significant and negative $(-.05 ; p=.00)$. The total effect was not significant.

\section{Moderating the Relationship Between Family SES and Sense of Poverty}

To determine whether family problem-solving and access to resources moderated the relationship between family SES and sense of poverty, hierarchical multiple regression was run. In the first regression, locale, difficulties, assets, family problem-solving, and access to resources were predictors. The model significantly explained $21.89 \%$ of the variance in sense of poverty, $F(5,825)=46.24, p=.00$. Except for access to resources, all predictors were significant: a greater sense of poverty was associated with Bacolod youth $(\beta=-.08, p=.01)$, with lesser family assets $(\beta=$ $-.13, p=.00)$, with greater financial difficulties $(\beta=.36$, $p=.00)$, and with less family problem-solving $(\beta=-.09$, $p=.00)$. The standard errors for the regression coefficients ranged from .03 to .04 .

In the second regression, the interaction of assets and financial difficulties with family problem-solving and with access to resources were added as predictors. None of the interaction effects were significant, indicating that neither family problem-solving nor access to resources moderated the relationship between family SES and sense of poverty; that is, the effects of assets and difficulties on sense of poverty were the same regardless of the extent of family problem-solving and access to resources. 


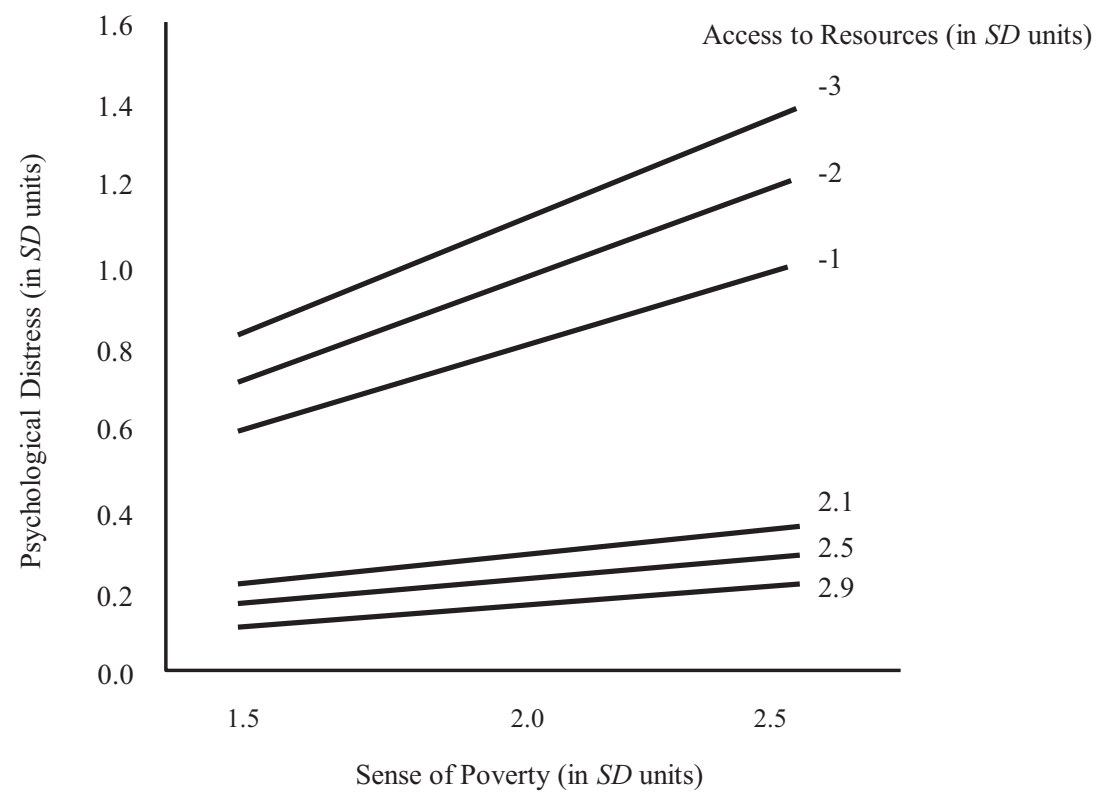

Figure 2

The moderating effect of access to resources on the relationship between sense of poverty and psychological distress.

\section{Moderating the Relationship Between Sense of Poverty and Distress}

Next, it was determined whether family problem-solving and access to resources moderated the relationship between sense of poverty and distress. In the first regression, sense of poverty, family problem-solving, and access to resources were entered as predictors. The model significantly explained $14.44 \%$ of the variance in distress, $F(3$, $827)=46.54, p=.00$. Except for access to resources, all predictors were significant: distress was associated with less family problem-solving $(\beta=-.16, S E=.03, p=.00)$ and with a keener sense of poverty $(\beta=.32, S E=.03$, $p=.00)$.

In the second regression, the interaction of sense of poverty with problem-solving and with access to resources were added as predictors. This model significantly explained $15.16 \%$ of the variance in distress, $F(5,825)=$ $29.48, p=.00$. The $.72 \%$ increase in variance explained from the first to the second regression was significantly greater than zero, $F(2,825)=3.50, p=.03$. The predictors that were significant in the first regression were also significant in the second regression. In addition, Sense of Poverty $\times$ Access to Resources was significant $(\beta=-.08$, $S E=.03, p=.00)$; Sense of Poverty $\times$ Problem-Solving was not.

The buffering effect of access to resources was evident when sense of poverty was higher than the mean; Figure 2 illustrates this moderating effect when sense of poverty is at $1.5,2$, and $2.5 S D$ units above the mean. A simple slopes analysis was done for cases where there was less access to resources (at $-3,-2$, and $-1 S D$ units below the mean) and where there was greater access (at 2.1, 2.5, and 2.9 SD units above the mean). The slopes were significantly positive given less access to resources, but were not significantly different from zero given greater access to resources. Thus, sense of poverty was associated with greater psychological distress only when there was little access to resources.

\section{Discussion}

The current research aimed to characterise how college youth's psychological distress is associated with the experience of poverty. It determined whether sense of poverty mediates the effect of family SES on distress; it also determined whether family problem-solving and access to services mitigate the effect of family SES on sense of poverty and the effect of sense of poverty on distress.

The current study has limitations such that caution needs to be exercised in interpreting the findings. One limitation was that few items were used to measure sense of poverty (three items) and distress (five items). Although the Social Weather Station surveys (Mangahas, 1999) used only two brief questions to measure self-rated poverty, the psychological nature of this study necessitated measuring sense of poverty more extensively. Another limitation was the yes-no response format used in measuring sense of poverty and distress. In both measures, adequate inter-item correlations for ranked data were obtained, but greater discrimination and precision in responses could have been obtained if, say, a 1-10 Likert-type scale was used instead.

The cross-sectional nature of the study, as opposed to a longitudinal one, does not warrant a definitive conclusion about a temporal, cause-effect relationship that proceeds from SES to sense of poverty to distress. If there were a 
cause-effect relationship, however, it would be more logical to assume that family SES caused sense of poverty and distress rather than the other way around. Admittedly, there remains the possibility that distress could have contributed to sense of poverty, although it was the reversed direction that was considered in this article.

\section{Sense of Poverty as a Possible Pathway from Financial Difficulties to Psychological Distress}

With assets and financial difficulties treated as separate variables (rather than as components of a singular SES score), the differential effects of SES were evident in the final path-analytic model. This model indicates that it is financial difficulties, more than lack of assets, that are associated with distress. Financial difficulties, however, do not have a direct effect on distress; rather, its effect is mediated by sense of poverty.

Does a lack of assets contribute to distress, albeit in a lesser degree than do financial difficulties? If only the indirect path through sense of poverty is considered, the answer is yes: the significant indirect effect of lack of assets on distress is smaller in magnitude than the indirect effect of financial difficulties. This negative indirect effect, however, is counteracted by a significant direct effect that is in the unexpected, positive direction; thus, the total effect is not significant.

Nevertheless, the counterintuitive result that more family assets are associated with greater distress is worth considering as it is reported, too, in extant literature. Socioeconomically affluent youth are at higher risk for substance abuse, anxiety, and depression (Luthar, 2003). The explanatory construct could be some inordinate preference for material goods, as suggested by the finding that wellbeing is associated with being less materialistic (Christopher, Kuo, Abraham, Noel, \& Linz, 2004; Karabati \& Cemalcilar, 2010; Piko, 2006; Tatzel, 2003).

It remains, however, that the salient implication of the path-analytic results is that sense of poverty provides a mediating mechanism from financial difficulties to distress. Sense of poverty is possibly associated with internalised classism. Instead of the poor being held down by others' biases against them, or by others' misconceptions of the roots of poverty, it is actually the poor's own sense of being poor that holds them down (Russell, 1996). Yet, the issue of social class and the concomitant internalised classism are not talked about between psychologists and their poor clients, even as talking about these would allow the clients to recognise that their views about their material circumstances could actually deter self-development (Russell, 1996; Spence, 2012).

\section{The Mitigating Role That Families and Social Resources Play}

The finding that family problem-solving is associated with youth's decreased sense of poverty and decreased distress suggests that addressing internalised classism among college youth is a family issue. The finding that family access to social resources buffers the effect of sense of poverty on distress suggests that addressing internalised classism among college youth is likewise a community and social issue.

That the issue of poverty is social in nature underscores structure and policy changes towards poverty alleviations (Seccombe, 2002). Government policies can be crafted to promote access to and confidence in various social services. Various program strategies should be explored that would lead, for example, to equitable distribution of resources to schools and communities (Blustein et al., 2002). Increasing access to educational assistance and scholarships would reap benefits, given that education leads to rising out of one's social class (Atal, 2005; Nelson et al., 2006; Tuason, 2008).

We acknowledge that addressing the structural and economic roots of poverty and social inequality is of prime importance but, given the scope of this article, we emphasise the psychological gain that can be had by strengthening family resources in terms of both collaborative problem-solving and access to services.

With poor youth at risk for numerous problems, including school failure, the family, schools and the community can work together in developing student resiliency programs (Benard, 1997). Schools can connect families to relevant community agencies (Benard, 1997); interventions can be designed that foster collaborative problemsolving among students, parents, teachers, and school personnel (Allen \& Graden, 2002); programs run by peers or professionals can help socially disadvantaged youth to adjust better to college life (Ostrove \& Long, 2007); therapists can help poor clients by being more familiar with the available social, medical, legal, and educational resources in the community (Kim \& Cardemil, 2012).

This study's finding regarding the family's contribution in deterring a sense of poverty and distress among the youth indicates the importance of interventions that target the family. Strengthening family resilience would give the youth a sense that their families can address their own problems (Walsh, 2002). Such family programs have been documented in literature: using the family systems approach in therapy with poor clients has been shown to work (Smith, 2005); family sessions involving psychoeducation in problem solving have effectively prevented depression among low-income mothers (Kim \& Cardemil, 2012).

\section{Social Change Initiatives With Poor College Youth}

While youth have shown themselves to be agents of their own development (Damon, 2004), support is needed and can be effective. As suggested by the current research, the family and its social networks are also agents of youth development. While the current research was not geared specifically towards action and social change, it can serve as impetus to an action research cycle for developing programmatic interventions at the university setting from which the researchers come from (Liu \& Bernardo, 2014), utilising family, school, and 
community resources. These resources might well be part of what Tickamyer and Duncan (1990) call opportunity structures. Opportunity structures embedded in the youth's social networks lend themselves easily to action research that puts a premium on the interconnectedness of individuals in social relations (Liu, Ng, Gastardo-Conaco, \& Wong, 2008). In this kind of action research, the youth, the family, and the community can emerge as inquiring coresearchers' (Reason \& Bradbury, 2008, p. 3). Of interest would be how the experience of material scarcity can provide the impetus for individual, family, and community growth.

\section{Acknowledgments}

Data-gathering was supported by a grant from the Office of the President, De La Salle University (DLSU) given to the DLSU Department of Psychology. The writing of this manuscript was supported by the Exaltacion C. Ramos Professorial Chair in Tests and Measurement given to Melissa Lopez Reyes. The authors thank Rowena Bañez, Rosario Chu, Jose Maria Diestro, Jr., Junie Go, Ramon Lachica, and Rowella Lopera for the coordination of data-gathering; Marie Rose Morales and May Ann Garo-Santiago for the preparation of the questionnaires; Charisse Yap Tan for administrative assistance; and Hannah Olivas for data management.

\section{References}

Adler, N.E., Epel, E.S., Castellazo, G., \& Ickovics, J.R. (2000). Relationship of subjective and objective social status with psychological and physiological functioning: Preliminary data in healthy white women. Health Psychology, 19, 586592.

Allen, S., \& Graden, J. (2002). Best practices in collaborative problem solving for intervention design. In. A. Thomas \& J. Grimes (Eds.), Best practices in school psychology IV (pp. 565-582). Washington, DC: National Association of School Psychologists.

American Psychological Association Task Force on Socioeconomic Status. (2007). Report of the APA Task Force on Socioeconomic Status. Washington, DC: American Psychological Association.

Atal, Y. (2005). Youth in Asia: An overview. In F. Gale \& S. Fahey (Eds.), Youth in transition: The challenges of generational change in Asia. Proceedings of the 15th Biennial General Conference of the Association of Asian Social Science Research Councils (pp. 9-21). Canberra, Australia: The Academy of the Social Sciences in Australia.

Benard, B. (1997). Turning it around for all youth: From risk to resilience. Retrieved from ERIC database (ED412309).

Blöndal, S., Field, S., \& Girouard, N. (2002). Investment in human capital through upper-secondary and tertiary education. OECD Economic Studies, 34, 41-89.

Blustein, D.L., Chaves, A.P., Diemer, M.A., Gallagher, L.A., Marshall, K.G., Sirin, S., \& Bhati, K.S. (2002). Voices of the forgotten half: The role of social class in the school-to- work transition. Journal of Counseling Psychology, 49, 311323

Christopher, A., Kuo, S.V., Abraham, K., Noel, L., \& Linz, H. (2004). Materialism and affective well-being: The role of social support. Personality and Individual Differences, 37, 463470.

Damon, W. (2004). What is positive youth development? The ANNALS of the American Academy of Political and Social Science, 591, 13-24. doi:10.1177/0002716203260092

De La Salle University Department of Psychology (2012). [College youth data set. Youth Development Research Project Phase 2]. Unpublished raw data.

de Leeuw, J. (2005). Nonlinear principal component anal$y$ sis and related techniques. University of California Los Angeles: Department of Statistics. Retrieved from: http://escholarship.org/uc/item/8bj075gv

de Vos, K. \& Garner, T.I. (1991). An evaluation of subjective poverty definitions: Comparing results from the US and the Netherlands. Review of Income and Wealth, 37, 267285.

Diemer, M.A., \& Ali, S.R. (2009). Integrating social class into vocational psychology: Theory and practice implications. Journal of Career Assessment, 17, 247-265. doi:10.1177/1069072708330462

Diemer, M., Mistry, R., Wadsworth, M., López, I., \& Reimers, F. (2013). Best practices in conceptualizing and measuring social class in psychological research. Analyses of Social Issues and Public Policy, 13, 77-113.

Guerrero, S. (1973). The 'Culture of Poverty' in metro Manila: Some preliminary notes. Philippine Sociological Review, 21, 215-221.

Harper, C., Marcus, R., \& Moore, K. (2003). Enduring poverty and the conditions of childhood: Life course and intergenerational poverty transmissions. World Development, 31, 535554.

Hill, J., Jobling, R., Pollet, T., \& Nettle, D. (2014). Social capital across urban neighbourhoods: A comparison of selfreport and observational data. Evolutionary Behavioral Sciences, 8(2), 59-69.

Hudson, J.(2006). Institutional trust and subjective well-being across the EU. Kyklos, 59, 43-62.

Jansen, A., Moses, M., Mujuta, S., \& Yu, D. (2013, September). Multifaceted poverty: Absolute, relative and subjective poverty in South Africa. Paper presented at the Biennial Conference of the Economic Society of South Africa, Bloemfontein, South Africa.

Johnson, S., Richeson, J., \& Finkel, E. (2011). Middle class and marginal? Socioeconomic status, stigma, and self-regulation at an elite university. Journal of Personality and Social Psychology, 100, 838-852.

Kanazawa, S., \& Savage, J. (2009) Why nobody seems to know what social capital is. Journal of Social, Evolutionary, and Cultural Psychology, 3, 118-132.

Karabati, S., \& Cemalcilar, Z. (2010). Values, materialism, and well-being: A study with Turkish university students. Personality and Individual Differences, 31, 624-633. 
Kim, S., \& Cardemil, E. (2012). Effective psychotherapy with low-income clients: The importance of attending to social class. Journal of Contemporary Psychotherapy, 42, 27-35.

Liu, J.H., \& Bernardo, A.B.I. (2014). Social psychology for social change: Foundations for and Introduction to a program of action-oriented research. Journal of Pacific Rim Psychology, $8(2), 29-34$.

Liu, J.H., Ng, S., Gastardo-Conaco, M.C., \& Wong, D.S.W. (2008). Action research: A missing component in the emergence of social and cross-cultural psychology as a fully interconnected global enterprise. Social and Personality Psychology Compass, 2/3, 1162-1181.

Luthar, S. (2003). The culture of affluence: Psychological costs of material wealth. Child Development, 74, 1581-1593.

McDonnough, P. (1997). Choosing colleges: How social class and schools structure opportunity. Albany, NY: SUNY Press Albany.

McLeod, J.D., \& Owens, T.J. (2004). Psychological well-being in the early life course: Variations by socioeconomic status, gender, and race/ethnicity. Social Psychology Quarterly, 67, 257-278.

Mangahas, M. (1999, July). Monitoring Philippine poverty by operational social indicators. Paper presented at the World Bank's Poverty Reduction and Economic Management (PREM) Network, Maryland, USA.

Moore, K. (2005, July). Thinking about youth poverty through the lenses of chronic poverty, life-course poverty and intergenerational poverty (Chronic Poverty Research Centre Working Paper 57). The University of Manchester: Chronic Poverty Research Centre.

National Statistical Coordination Board. (2014). Poverty indicators. Retrieved from http://www.nscb.gov.ph/poverty/

National Statistics Office. (2012). 2012 Family income and expenditure survey. Final report. Manila, Philippines: Author.

National Statistics Office. (2010). 2010 Annual poverty indicators survey. Final report. Manila, Philippines: Author.

Nelson, M.L., Englar-Carlson, M., Tierney, S.C., \& Hau, J.M. (2006). Class jumping into academia: Multiple identities for counseling academics. Journal of Counseling Psychology, 53, $1-14$.

Oakes, J.M., \& Rossi, P.H. (2003). The measurement of SES in health research: Current practice and steps toward a new approach. Social Science \& Medicine, 56, 769-784.

Ostrove, J.M., \& Long, S.M. (2007). Social class and belonging: Implications for college adjustment. The Review of Higher Education, 30, 363-389.

Piko, B. (2006). Satisfaction with life, psychosocial health and materialism among Hungarian youth. Journal of Health Psychology, 11, 827-831.

Psacharopoulos, G. (1994). Returns to investment in education: A global update. World Development, 22, 1325-1343.

Reason, P., \& Bradbury, H. (2008). The SAGE handbook of action research. London: Sage Publications.

Reyes, M.L., Garo-Santiago, M.A., Sta. Maria, M.A., \& the De La Salle University Department of Psychology (2011). The multicontext assessment battery of youth development. Unpublished manuscript, Department of Psychology, De La Salle University, Manila, Philippines.

The Republic of the Philippines Official Gazette. (2012). The $\mathrm{K}$ to 12 Basic Education Program. Retrieved from http://www.gov.ph/k-12/\#about.

Romulo, M. (2014, January). SWS survey: More households poor, hungry at the end of 2013. Rappler. Retrieved from http://www.rappler.com/move-ph/issues/hunger/47956sws-survey-more-households-poor-hungry-2013

Russell, G.M. (1996). Internalized classism: The role of class in the development of self. Women \& Therapy, 18, 59-71.

Seccombe, K. (2002). 'Beating the odds' versus 'changing the odds': Poverty, resilience, and family policy. Journal of Marriage and Family, 64, 384-394

Shek, D.T.L. (2004). Beliefs about causes of poverty and psychological well-being of parents and adolescents experiencing economic disadvantage in Hong Kong. The American Journal of Family Therapy, 32, 239-254.

Sicat, G.P. (2014, April). Income inequality — A helicopter view. Philippine Star. Retrieved from http://www.philstar. com/business/2014/04/09/1310376/income-inequalityhelicopter-view

Singh-Manoux, A., Marmot, M.G., \& Adler, N.E. (2005). Does subjective social status predict health and change in health status better than objective status? Psychosomatic Medicine, $67,855-861$.

Smith, L. (2005). Psychotherapy, classism, and the poor: conspicuous by their absence. American Psychologist, 60, 687-696.

Spence, N. (2012). Cultural competence: Social class - The forgotten component. Clinical Psychology Forum, 230, 3639.

Tatzel, M. (2003). The art of buying: Coming to terms with money and materialism. Journal of Happiness Studies, 4, 405435.

The World Bank. (2001a). Philippines poverty assessment. Volume I: Main report. Pasig City, Philippines: World Bank Office Manila.

The World Bank. (2001b). Philippines poverty assessment. Volume II: Methodology. Pasig City, Philippines: World Bank Office Manila.

The World Bank. (2014). Philippines data. Retrieved from http://data.worldbank.org/country/philippines

Tickamyer, A. \& Duncan, C. (1990). Poverty and opportunity structure in rural America. Annual Review of Sociology, 16, 67-86.

Tuason, M.T. (2002). Culture of poverty: Lessons from two case studies of poverty in the Philippines; One Became Rich, the Other One Stayed Poor. Online Readings in Psychology and Culture, 8(1). Retrieved from http://dx.doi.org/10.9707/2307-0919.1069

Tuason, M.T. (2008). Those who were born poor: A qualitative study of Philippine poverty. Journal of Counseling Psychology, 55(2), 158-171.

Valencia-Garcia, D., Simoni, J., Alegria, M., \& Takeuchi, D. (2012). Social capital, acculturation, mental health, and 
perceived access to resources among Mexican American women. Journal of Latina/o Psychology, 1,78-89.

Walpole, M.B. (2003). Socioeconomic status and college: How SES affects college experiences and Outcomes. The Review of Higher Education, 27, 45-73.

Walpole, M.B., (2008). Emerging from the pipeline: African American students, socioeconomic status, and college ex- periences and outcomes. Research on Higher Education, 49, 237-255.

Walsh, F. (2002). A family resilience framework: Innovative practice applications. Interdisciplinary Journal of Applied Family Studies, 51(2), 130-137.

Walsh, F. (2003). Family resilience: A framework for clinical practice. Family Process, 42, 1-18. 